\title{
The Impact of Total Intravenous Propofol Anaesthesia versus Sevoflurane Anaesthesia on Perioperative Pain in Patients Undergoing Colonic Cancer Surgery
}

\author{
Bahaa Gamal Saad*, Samy Abdelrahman Amr, Ashraf Amin Mohammed, \\ Montaser Abdelfattah Mohammed
}

Department of Anesthesia, Intensive Care and Pain Management, South Egypt Cancer Institute, Assuit University, Assuit, Egypt Email: *bahaagamal@aun.edu.eg

How to cite this paper: Saad, B.G., Amr, S.A., Mohammed, A.A. and Mohammed, M.A. (2021) The Impact of Total Intravenous Propofol Anaesthesia versus Sevoflurane Anaesthesia on Perioperative Pain in Patients Undergoing Colonic Cancer Surgery. Open Journal of Anesthesiology, 11, $1-11$.

https://doi.org/10.4236/ojanes.2021.111001

Received: November 26, 2020

Accepted: January 9, 2021

Published: January 12, 2021

Copyright ( 2021 by author(s) and Scientific Research Publishing Inc. This work is licensed under the Creative Commons Attribution International License (CC BY 4.0).

http://creativecommons.org/licenses/by/4.0/ (c) (i) Open Access

\begin{abstract}
Background: Cancer colon is one of the most common malignancies. After colon cancer surgery patients may experience severe pain. Several studies have reported that a significant decrease in postoperative pain with propofol while other studies have showed this effect was not significant. Aim: Our goal was to assess the effect of combined epidural anaesthesia either with propofol or sevoflurane on intraoperative fentanyl consumption and postoperative pain in patients undergoing open surgical resection of colon cancer. Patients and Methods: 48 adult patients suffering from cancer colon scheduled for open surgical resection randomly allocated either to receive epidural-propofol by total intra venous anaesthesia (TIVA) $(n=24)$ or epidural-sevoflurane anaesthesia $(n=24)$, intraoperative heart rate and fentanyl consumption and postoperative pain score (verbal analogue scale, 0 - 10) were recorded. Results: In our study we found that the intensity of postoperative pain was low in all patients and the propofol based anaesthesia had relatively lower pain scores up to $24 \mathrm{hrs}$ postoperatively in comparison to sevoflurane based anaesthesia, intraoperative fentanyl consumption was lower with sevoflurane and heart rate lower with propofol group. Conclusions: we recommend that use of multimodal analgesia decrease postoperative pain in all cancer colon patients undergoing open surgery who anaesthetized with either propofol or sevoflurane. Also use of propofol showed better analgesic outcomes postoperatively.
\end{abstract}

\section{Keywords}

Cancer Colon, Epidural Anesthesia, Propofol, Sevoflurane, Postoperative Pain 


\section{Introduction}

Globally more than 1 million people get colorectal cancer every year resulting in about 715,000 deaths as of 2010 up from 490,000 in 1990 [1]. As of 2012, it is the second most common cause of cancer in women (9.2\% of diagnoses) and the third most common in men (10.0\%) with it being the fourth most common cause of cancer death after lung, stomach, and liver cancer [2].

Surgery is the primary treatment for colon cancer, postoperative pain after open surgery for cancer colon is not controlled by simple analgesic that requires a well postoperative analgesia. However recent protocols, postoperative pain management remain a big challenge [3] [4].

The use of intraoperative general anesthetics, either injectable (propofol) or volatile (sevoflurane), could influence peripheral nociception, thereby controlling postoperative pain.

Propofol for total intravenous injection and sevoflurane for inhalation anesthesia are mainly used in general anesthesia because their pharmacological properties facilitate rapid recovery after anesthesia. Propofol is superior in recovering features and reducing postoperative adverse reactions [5]. Sevoflurane is volatile, nonflammable and aromatic, non-irritating to the respiratory tract, and has low blood gas partition coefficient, which is conducive to the regulation of anesthesia depth, smooth induction and rapid recovery [6].

In some studies, showed that propofol-based anesthesia was associated with decreased postoperative pain compared with that associated with volatile agent-based anesthesia [7] [8] [9].

While other studies found no evidence that propofol was superior than inhalational anaesthesia [10] [11].

There was a recent meta-analysis, that showed that was no significant differences between propofol and inhalational anesthesia (isoflurane, sevoflurane, and desflurane) were identified in controlling postoperative pain ,this was possibly due to substantial heterogeneity between the studies included [12].

In the present study, we aimed to evaluate the effect of epidural-propofol based anesthetic technique on postoperative pain and intraoperative fentanyl consumption and heart rate in comparison to epidural-sevoflurane based anesthesia in patients undergoing open surgical resection of colon cancer.

\section{Patients and Methods}

This study was conducted in South Egypt Cancer Institute, Assuit University, Assuit, Egypt, between April 2018 and August 2020.

After obtaining the ethical committee approval of our institutional review board and signed informed written consent from each patient, which included explanation of the procedure, the benefits, the risks, and the alternatives, $48 \mathrm{pa}-$ tients scheduled for open surgical resection of cancer colon will be consecutively enrolled. The inclusion criteria were adult patients aged 20 - 70 yrs, ASA class I and II and scheduled for elective open surgery for non-metastatic cancer colon 
stage I, II.

The exclusion criteria were patient refusal, known allergy to the study medications, patients with compromised immune function (associated blood diseases, immunosuppressive drugs, chemotherapeutic agents, corticosteroids) and contraindications to epidural insertion e.g. infection at insertion site and coagulopathy. Patients were randomly assigned to 2 equal groups, using a computer-generated list of numbers that were masked in opaque sealed envelopes and opened before the procedure. Preoperative assessment for all patients include: 1-Physical fitness. 2-Laboratory investigations (CBC, prothrombin time and concentration, urea and creatinine, blood glucose level and liver function). $\mathrm{Pa}$ tients were be randomly allocated into two groups, 24 patients for each one.

Inhalational Group (A): patients received epidural-inhalational based anesthetic technique and postoperative analgesia through patient controlled epidural analgesia. General anesthesia was induced by fentanyl $1 \mu / \mathrm{kg}$ with 1 MAC sevoflurane, endotracheal intubation was facilitated as group (EP) and maintenance was made by sevoflurane. At the end of surgery, muscle relaxation reversed by neostigmine $0.05 \mathrm{mg} / \mathrm{kg}$ and atropine $0.01 \mathrm{mg} / \mathrm{kg}$.

Propofol Group (B): patients received epidural-propofol based anesthetic technique and postoperative analgesia through patient controlled epidural analgesia. General anesthesia was induced by propofol $2 \mathrm{mg} / \mathrm{kg}$ and fentanyl 1 $\mu / \mathrm{kg}$. Endotracheal intubation was facilitated with administration of cis-atracurium $0.3 \mathrm{mg} / \mathrm{kg}$ followed by cis-atracurium $0.15 \mathrm{mg} / \mathrm{kg}$ on demand throughout the operation, maintenance of anesthesia was accomplished by I V propofol 3 $10 \mathrm{mg} / \mathrm{kg} / \mathrm{h}$ and was titrated to maintain adequate anesthetic depth with fentanyl $0.5 \mu / \mathrm{kg} / \mathrm{hr}$. Thoracic epidural block was performed in the operative unit under complete aseptic conditions under standard ASA monitoring. In the preoperative room, basic monitoring probes were attached. Each patient's blood pressure, peripheral oxygen saturation, and ECG were monitored by an anesthesiologist before and during the intervention. IV $18 \mathrm{G}$ cannula was inserted and $1 \mathrm{~L}$ of normal saline was infused. The patient is positioned in sitting position with the head fully flexed on the neck. After sterilization of the area of injection and using complete aseptic technique, the skin point of puncture is infiltrated with $2 \%$ lidocaine. Before induction of anesthesia, the epidural catheter was placed midway at the inter-vertebral thoracic space between $\mathrm{T} 9$ and T11 in patients for left-sided resections and between T8 and T10 in patients for right-sided resections. After testing dose of $2 \mathrm{ml}$ of adrenaline 1:100,000 and lidocaine $2 \%$ to ensure the site of the catheter, patients received a bolus of $7 \mathrm{ml} 0.25 \%$ bupivacaine and fentanyl $2 \mu / \mathrm{ml}$ to obtain sensory level at T4, within 15 minutes, if the sensory level was below T4 another $1 \mathrm{ml} /$ segment was delivered through the catheter. After adequate recovery from anesthesia, all patients were transferred to post anesthesia care unit. Postoperative analgesia for both groups was done by patient controlled epidural analgesia, with constant infusion of $7 \mathrm{ml}$ of $0.125 \%$ bupivacaine and $2 \mu / \mathrm{ml}$ fentanyl, $7 \mathrm{ml}$ boluses 
and a 15-min lockout time. Patients were followed up for analgesia, efficacy, side effects, and complications for the first $24 \mathrm{hrs}$. The pain intensity was measured by VAS (0-10), the subjects were instructed that if 0 represented no pain and 10 represented the worst imaginable pain and they should know how to perform it correctly. Heart rate and fentanyl consumption during operation were reported.

\section{Statistical Analysis}

All data were collected and cleaned by Excel program ${ }^{\circledR}$ then analyzed with SPSS ${ }^{\circ}$ software version 23.0 was used for data management and data analysis. Mean \pm standard deviation, median and range when appropriate described quantitative data. Numbers with percentages described qualitative data. The chi-square test will be used for comparing independent categorical variables. The Mann-Whitney U-test, Wilcoxon Signed Ranks Test and Friedman's test will be performed for the numerical variables not displaying normal distribution. Independent samples T-test was performed for the numerical variables displaying normal distribution. $P$ value was two tailed and considered significant at 0.05 level.

\section{Results}

About 89 patients evaluated, 70 of them were identified to be eligible and randomly assigned to two groups. Of those excluded from the study, 19 failed to meet the inclusion criteria (11 due to ASA $\geq$ III, SAP $>180 \mathrm{mmHg}$, cardiopulmonary disease, or chronic renal disease, 6 due to change in surgical approach or cancellation of procedure) and 2 refused to enroll. After excluding 22 patients for various reasons, 48 patients remained till the study end. In those who left the study prematurely, PCA was terminated early in 5 patients, surgical procedures were switched intraoperatively in 9 patients, 6 patients underwent reoperation, and 2 patients were died from postoperative hemorrhage on the first postoperative day. Twenty four patients in each group remained in the final analyses.

All patients completed the study according to the protocol. All procedures were performed by the same team.

Patient characteristics of the 2 study groups are compared regarding: sex, diagnosis either rt colon, lt colon, sigmoid, transverse colon, hepatic flexure or splenic flexure and ASA classification and showed no significant difference between them (Table 1 and Figures 1-3).

Comparison of Operative data among the 2 study groups showed no significant difference (Table 2).

The propofol group had lower HRs compared to the sevoflurane group (80.96) \pm 15.07 vs. $(74.71) \pm 17.26$ beats $/ \mathrm{min}, \mathrm{P}=0.188$ (Table 2).

Intraoperative fentanyl consumption was lower insevoflurane group compared to propofol group (157.71) \pm 55.05 vs. $(223.13) \pm 48.23$ micg $\mathrm{P}<0.001$ (Table 2 and Figure 4).

Regarding measurement of pain intensity by VAS score, we measured from 4 
Table 1. Patient characteristics of the 2 study groups.

\begin{tabular}{|c|c|c|c|c|c|c|}
\hline & & \multicolumn{4}{|c|}{ Group } & \multirow{3}{*}{$P$ value } \\
\hline & & \multicolumn{2}{|c|}{$\begin{array}{l}\text { A (inhalation } \\
\text { sevoflurane) }\end{array}$} & \multicolumn{2}{|c|}{$\begin{array}{l}\text { B (intravenous } \\
\text { propofol) }\end{array}$} & \\
\hline & & Count & $\%$ & Count & $\%$ & \\
\hline \multirow{3}{*}{ Sex } & Female & 8 & 33.3 & 14 & 58.3 & \multirow{3}{*}{0.147} \\
\hline & Male & 16 & 66.7 & 10 & 41.7 & \\
\hline & Total & 24 & 100.0 & 24 & 100.0 & \\
\hline \multirow{7}{*}{ Diagnosis } & RT colon & 8 & 33.3 & 5 & 20.8 & \multirow{7}{*}{0.896} \\
\hline & LT colon & 6 & 25.0 & 6 & 25.0 & \\
\hline & sigmoid colon & 8 & 33.3 & 9 & 37.5 & \\
\hline & Transverse colon & 1 & 4.2 & 2 & 8.3 & \\
\hline & Hepatic flexure & 1 & 4.2 & 1 & 4.2 & \\
\hline & splenic flexure & 0 & 0.0 & 1 & 4.2 & \\
\hline & Total & 24 & 100.0 & 24 & 100.0 & \\
\hline \multirow{3}{*}{ ASA } & I & 14 & 58.3 & 16 & 66.7 & \multirow{3}{*}{0.766} \\
\hline & II & 10 & 41.7 & 8 & 33.3 & \\
\hline & Total & 24 & 100.0 & 24 & 100.0 & \\
\hline
\end{tabular}

$P$ value is significant $\leq 0.05$ Chi-square test.

Table 2. Comparison of operative data among the 2 study groups.

\begin{tabular}{|c|c|c|c|c|c|}
\hline & \multicolumn{4}{|c|}{ Group } & \multirow{3}{*}{$P$ value } \\
\hline & \multicolumn{2}{|c|}{$\begin{array}{l}\text { A (inhalation } \\
\text { sevoflurane) }\end{array}$} & \multicolumn{2}{|c|}{$\begin{array}{l}\text { B (intravenous } \\
\text { propofol) }\end{array}$} & \\
\hline & Mean & $\begin{array}{c}\text { Std. } \\
\text { Deviation }\end{array}$ & Mean & $\begin{array}{c}\text { Std. } \\
\text { Deviation }\end{array}$ & \\
\hline Duration of surgery (hr.) & 3.03 & 0.74 & 2.92 & 0.95 & 0.645 \\
\hline Duration of anesthesia (hr.) & 3.48 & 1.04 & 3.46 & 0.96 & 0.943 \\
\hline HR per min & 80.96 & 15.07 & 74.71 & 17.26 & 0.188 \\
\hline $\begin{array}{l}\text { Intraoperative fentanyl } \\
\text { consumption (mic g) }\end{array}$ & 157.71 & 55.05 & 223.13 & 48.23 & $<0.001$ \\
\hline
\end{tabular}

$P$ value is significant $\leq 0.05$ Independent samples T-test.

to 24 hours postoperative in both study groups.

We found that for VAS score with sevoflurane group, there was a highly significant drop in pain score between that assessed after 4 hours and those after 20 and 24 hours, and for the second group with propofol, also there was a highly significant drop in pain score but only after 24 hours (Table 3 and Figure 5) (All pairwise comparisons were Bonferroni adjusted). When comparing VAS at each time point between the two study groups no significant difference was found.

Side effects and complications as: postoperative nausea and vomiting and haemodynamic changes, we found that 3 patients only complained in sevoflurane 
Table 3. VAS score from 4 to 24 hours postoperative in both study groups.

\begin{tabular}{ccccccccc}
\hline \multirow{2}{*}{ Group } & & $\begin{array}{c}\text { VAS.4 } \\
\text { hr. }\end{array}$ & $\begin{array}{c}\text { VAS.8 } \\
\text { hr. }\end{array}$ & $\begin{array}{c}\text { VAS.12 } \\
\text { hr. }\end{array}$ & $\begin{array}{c}\text { VAS.16 } \\
\text { hr. }\end{array}$ & $\begin{array}{c}\text { VAS.20 } \\
\text { hr. }\end{array}$ & $\begin{array}{c}\text { VAS.24 } \\
\text { hr. }\end{array}$ & $\begin{array}{c}\text { P value for } \\
\text { within groups, } \\
\text { time effect }\end{array}$ \\
\hline $\begin{array}{c}\text { A } \\
\text { (inhalation } \\
\text { sevofluran) }\end{array}$ & Median & 1.00 & 1.00 & 1.00 & 1.00 & 0.00 & 0.00 & \\
\hline Bange & $0-6$ & $0-6$ & $0-6$ & $0-5$ & $0-5$ & $0-6$ & $<0.001^{*}$ \\
$\begin{array}{c}\text { (intravenous } \\
\text { propofol) }\end{array}$ & Mean & 1.62 & 1.08 & 1.17 & 1.00 & 0.63 & 0.63 & \\
\hline $\begin{array}{c}\text { P value } \\
\text { between } \\
\text { groups }\end{array}$ & Mean & 1.29 & 1.08 & 1.00 & 0.92 & 0.75 & 0.42 & \\
\hline
\end{tabular}

For VAS score with inhalation type, there was a highly significant drop in pain score between that assessed after 4 hours and those after 20 and 24 hours. For the second group with intravenous type, also there was a highly significant drop in pain score but only after 24 hours. When comparing VAS at each time point between the two study groups no significant difference was found. P value is significant $\leq 0.05$. Mann-Whitney $\mathrm{U}$ test ${ }^{*}$ Friedman's test.

\section{Gender}

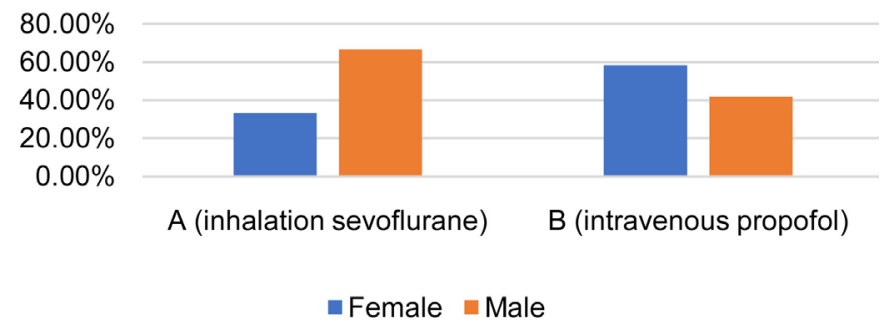

Figure 1. Side by side bar graph showing gender distribution between two studied groups, as regard sex, there was no significant difference between groups.

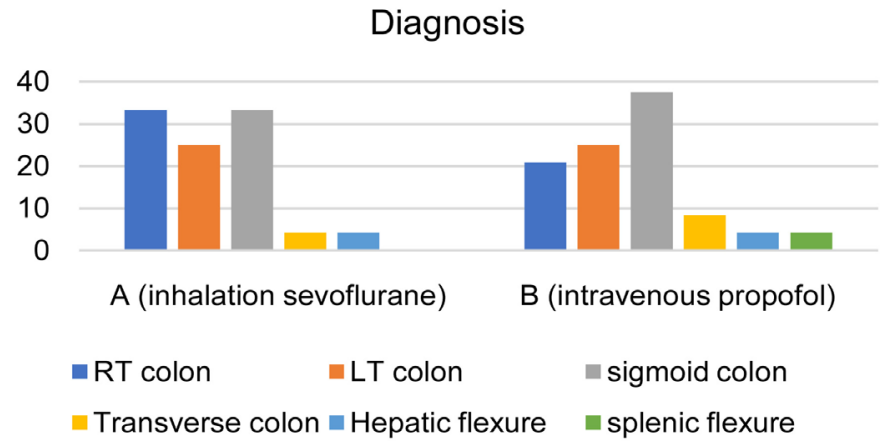

Figure 2. Side by side bar graph showing diagnosis distribution between two studied groups, there was no significant difference between groups regarding diagnostic site.

group from nausea and vomiting as $13 \%$ of total number of this group but no any patient inpropofol group complained from postoperative nausea and vomiting, so no significance difference between the two groups, and regarding 
ASA

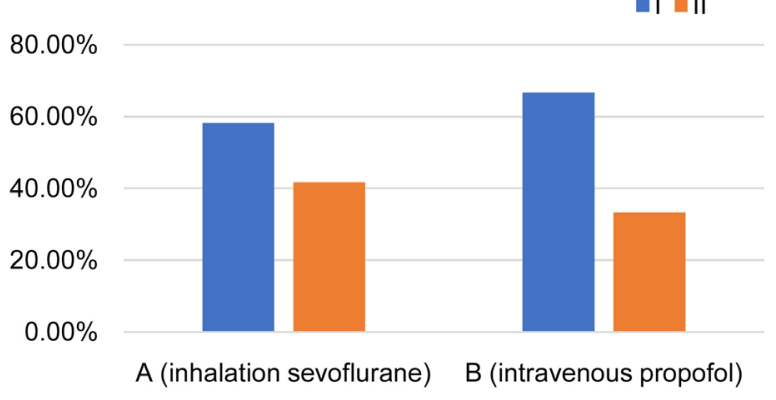

Figure 3. Side by side bar graph showing ASA distribution between two studied groups, regarding ASA, no difference between groups significantly.

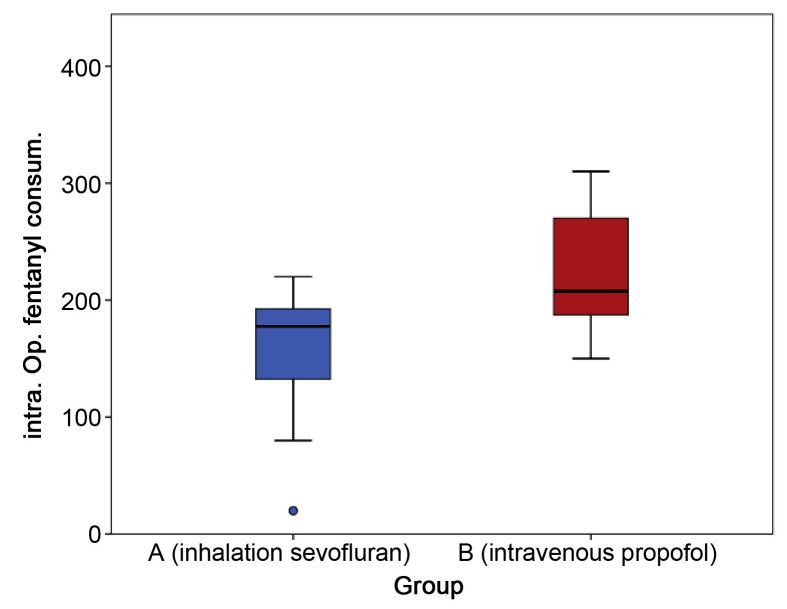

Figure 4. Box-and-whisker plot showing Intraoperative fentanyl consumption (mg) distribution between two studied groups, there was a significant difference between groups as marked decrease in sevoflurane group.

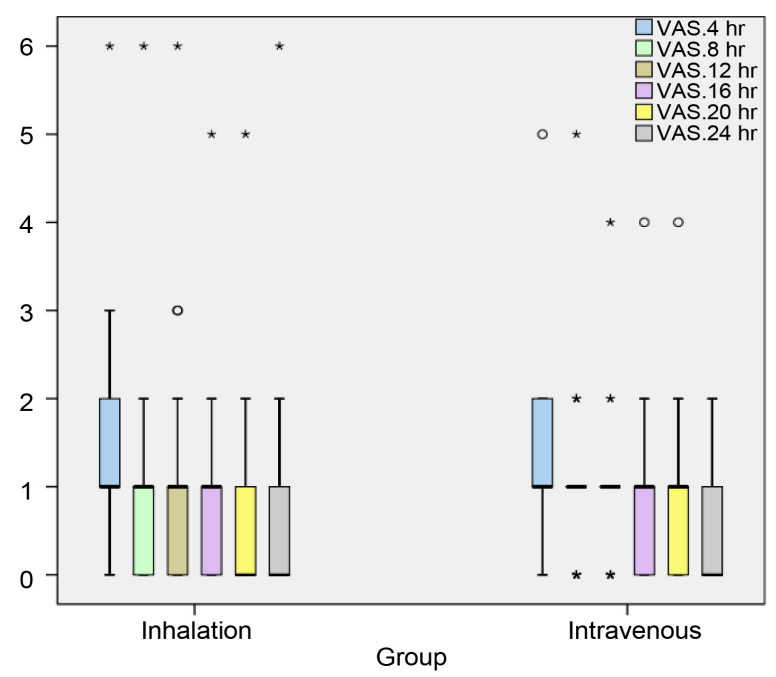

Figure 5. Box-and-whisker plot showing VAS score postoperative distribution between two studied groups, as we found marked decrease in VAS score in both groups. 
haemodynamic changes, there were no significant changes among both groups with no significant difference between them.

For VAS score with inhalation type, there was a highly significant drop in pain score between that assessed after 4 hours and those after 20 and 24 hours.

For the second group with intravenous type, also there was a highly significant drop in pain score but only after 24 hours. When comparing VAS at each time point between the two study groups no significant difference was found.

\section{Discussion}

Colorectal cancer (CRC) is the third most common malignant tumor in the world and the fourth leading cause of cancer death, with approximately 1.4 million new cases and nearly 700,000 deaths in 2012 [13]. There are two main techniques for anesthesia: 1) General anesthesia, where gas or intravenous drugs achieve central nervous system depression and 2) local anesthesia, where the drug is directly administered to the spinal cord or nerve to locally block the input of afferent and efferent nerve [14]. Epidural anesthesia and analgesia are commonly used to manage postoperative pain after abdominal surgery. Afferent block induced by epidural anesthesia can reduce neuroendocrine stress during and after surgery. Epidural anesthesia can reduce neuroendocrine stress and prevent immune suppression caused by surgery and general anesthesia [15].

The study was carried out in of South Egypt Cancer Institute hospital. After informed consent, a prospective randomized comparative study started by 48 patients scheduled for open surgical resection of cancer colon, were assigned randomly into two groups, twenty-four patients in each group, then evaluated as regards their patient characteristics, operative data, pain intensity using VAS score from 4 to 24 hours postoperative. Patients were divided into two groups; 24 patients for each one. Group A received epidural-sevoflurane and Group B received epidural-propofol.

In our study, basic preoperative data were compared between the 2 groups. It was found that no significant differences in age, gender, diagnosis, ASA, weight and height. We describe the results of operative data, intraoperative fentanyl consumption (micg) was higher in Group B than Group A ( $p<0.001$ ), in contrast, it was found that was no statistically significant difference regarding duration of surgery (hr.), duration of anesthesia (hr.), and HR per min was lower in Group B in comparison to Group A.

Concerning of intraoperative fentanyl consumption (micg); in Group A it estimated mean of $(157.71 \pm 55.05) \mathrm{mg}$ and in Group B it estimated mean of (223.13 \pm 48.23$) \mathrm{mg}$. Similar observations were reported by other study Ji et al. had reported that the intraoperative fentanyl consumption was also higher for the propofol group compared to the sevoflurane group; $\mathrm{P}=0.002$ [16].

As regard heart rate; in Group A it estimated mean of (80.96 \pm 15.07$)$ min. and in Group B it estimated mean of $(74.71 \pm 17.26)$ min. Similar observations were reported by other studies [17] [18] [19]. In the present study, a comparison 
was made between the $\mathrm{A}$ and $\mathrm{B}$ groups in the treatment of colon cancer. As regards pain relief, there was no statistically improvement in VAS at each time point between both groups throughout the follow-up period; follow-up was scheduled on the 4 hours, at 8 hours, at 12 hours, at 16 hours, 20 hours and 24 hours after the procedure. The VAS score range of patients after operation by 24 hours showed that propofol had a better analgesic effect $(0-4)$ vs $(0-6)$. For more analysis, our data, the VAS score at different times were compared in the same group for A and B groups. As regards pain relief, there was a statistically significant improvement in VAS in same group throughout the follow-up period $(P<0.001)$. In Group A we showed that there was a highly significant drop in pain score between that assessed after 4 hours and those after 20 and 24 hours. Our findings on Group B showed that, there was a highly significant drop in pain score but only after 24 hours. A similar pattern of results was obtained in [20] [21]. Propofol is preferred over inhalation anesthetics. In addition to its anesthetic and anti-emetic effects, anti-nociceptive effects of propofol are well known. In a group of healthy volunteers for whom acute pain was induced by intracutaneous electrical stimulation, the use of propofol lowered pain scores by $38 \%$ and reduced areas of hyperalgesia and allodynia [22]. Sevoflurane has comparable analgesic properties as well. At an optimal concentration of $0.8 \%$, it has been recommended for sedation during labor pain. However, inhalation anesthetics have been reported to have hyperalgesia effects at a minimum alveolar concentration of 0.1 , which may account for increased pain perception. The effects of volatile anesthetics may be moderated by the modulation of serotonin (5-HT3) receptor-mediated currents and by central adrenergic and cholinergic transmission [23].

\section{Limitation}

This study has several limitations. First, the study considered only those patients who underwent radical colonic cancer surgery, and so the findings cannot begeneralized to other types of surgeries. Second, due to its relatively small sample size, the study may have had potential bias. The study did not have significant power to detect differences between the groups over a long term postoperatively, including chronicpain. Lastly, although a reduction in postoperative was noted for the propofol group as compared to the sevoflurane group, we caution that clinical differences may not be as much as statistical differences.

\section{Conclusion}

In this single study, pain after open surgery for cancer colon was significantly reduced in all patients anesthetized with combined epidural with either propofol or sevoflurane, so we recommend that use of multimodal analgesia decrease postoperative pain in all cancer colon patients undergoing open surgery. Also use of propofol showed better analgesic outcomes postoperatively. However, due to the limitation in the enrollment of participants to this study, more evidence is 
required to further establish power for our results.

\section{Acknowledgements}

This paper is part of MD thesis. It is approved by ethical approval of institutional review board of South Egypt Cancer Institute at Assuit University and funded by research unit of South Egypt Cancer Institute at Assuit University. All authors have no conflict of interest regarding publishing this paper.

\section{Conflicts of Interest}

The authors declare no conflicts of interest regarding the publication of this paper.

\section{References}

[1] Lozano, R., Naghavi, M., Foreman, K., et al. (2012) Global and Regional Mortality from 235 Causes of Death for 20 Age Groups in 1990 and 2010: A Systematic Analysis for the Global Burden of Disease Study 2010. The Lancet, 380, 2095-2128.

[2] WHO (2010) Cancer. World Health Organization, Geneva.

[3] Argoff, C.E. (2014) Recent Management Advances in Acute Postoperative Pain. Pain Practice, 14, 477-487. https://doi.org/10.1111/papr.12108

[4] Wu, C.L. and Raja, S.N. (2011) Treatment of Acute Postoperative Pain. The Lancet, 377, 2215-2225. https://doi.org/10.1016/S0140-6736(11)60245-6

[5] Goswami, U., Babbar, S. and Tiwari, S. (2015) Comparative Evaluation of the Effects of Propofol and Sevoflurane on Cognitive Function and Memory in Patients Undergoing Laparoscopic Cholecystectomy: A Randomised Prospective Study. Indian Journal of Anaesthesia, 59, 150. https://doi.org/10.4103/0019-5049.153036

[6] Lokhat, D., Golandaj, A. and Ramjugernath, D. (2016) Scale-Up of Sevoflurane Synthesis: Selection of Chemical Route and Influence of Reagent Characteristics. International Journal of Applied Chemistry, 12, 455-461.

[7] Cheng, S.S., Yeh, J. and Flood, P. (2008) Anesthesia Matters: Patients Anesthetized with Propofol Have Less Postoperative Pain than Those Anesthetized with Isoflurane. Anesthesia \& Analgesia, 106, 264-269. https://doi.org/10.1213/01.ane.0000287653.77372.d9

[8] Li, M., Mei, W., Wang, P., et al. (2012) Propofol Reduces Early Post-Operative Pain after Gynecological Laparoscopy. Acta Anaesthesiologica Scandinavica, 56, 368-375. https://doi.org/10.1111/j.1399-6576.2011.02603.x

[9] Tan, T., Bhinder, R., Carey, M. and Briggs, L. (2010) Day-Surgery Patients Anesthetized with Propofol Have Less Postoperative Pain than Those Anesthetized with Sevoflurane. Anesthesia \& Analgesia, 111, 83-85. https://doi.org/10.1213/ANE.0b013e3181c0ee9e

[10] Fassoulaki, A., Melemeni, A., Paraskeva, A., Siafaka, I. and Sarantopoulos, C. (2008) Postoperative Pain and Analgesic Requirements after Anesthesia with Sevoflurane, Desflurane or Propofol. Anesthesia \& Analgesia, 107, 1715-1719. https://doi.org/10.1213/ane.0b013e318182d84e

[11] Pokkinen, S.M., Yli-Hankala, A. and Kalliomki, M.L. (2014) The Effects of Propofol vs. Sevoflurane on Post-Operative Pain and Need of Opioid. Acta Anaesthesiologica Scandinavica, 58, 980-985. https://doi.org/10.1111/aas.12366 
[12] Peng, K., Liu, H.Y., Wu, S.R., Liu, H., Zhang, Z.C. and Ji, F.H. (2016) Does Propofol Anesthesia Lead to Less Postoperative Pain Compared with Inhalational Anesthesia? A Systematic Review and Meta-Analysis. Anesthesia \& Analgesia, 123, 846-858. https://doi.org/10.1213/ANE.0000000000001504

[13] Arnold, M., Sierra, M.S., Laversanne, M., Soerjomataram, I., Jemal, A. and Bray, F. (2017) Global Patterns and Trends in Colorectal Cancer Incidence and Mortality. Gut, 66, 683-691. https://doi.org/10.1136/gutjnl-2015-310912

[14] Block, B.M., Liu, S.S., Rowlingson, A.J., Cowan, A.R., Cowan Jr., J.A. and Wu, C.L. (2003) Efficacy of Postoperative Epidural Analgesia: A Meta-Analysis. JAMA, 290, 2455-2463. https://doi.org/10.1001/jama.290.18.2455

[15] Miller, K.D., Siegel, R.L., Lin, C.C., Mariotto, A.B., Kramer, J.L., Rowland, J.H., Stein, K.D., Alteri, R. and Jemal, A. (2016) Cancer Treatment and Survivorship Statistics. CA: A Cancer Journal for Clinicians, 66, 271-289.

[16] Ji, F.-H., Wang, D., Zhang, J., Liu, H.-Y. and Peng, K. (2018) Effects of Propofol Anesthesia versus Sevoflurane Anesthesia on Postoperative Pain after Radical Gastrectomy: A Randomized Controlled Trial. Journal of Pain Research, 11, 1247. https://doi.org/10.2147/JPR.S164889

[17] Tylman, M., Sarbinowski, R., Bengtson, J.P., Kvarnstrom, A. and Bengtsson, A. (2011) Inflammatory Response in Patients Undergoing Colorectal Cancer Surgery: The Effect of Two Different Anesthetic Techniques. Minerva Anestesiologica, 77, 275-282.

[18] Enlund, M., Berglund, A., Andreasson, K., Cicek, C., Enlund, A. and Bergkvist, L. (2014) The Choice of Anaesthetic-Sevoflurane or Propofol-And Outcome from Cancer Surgery: A Retrospective Analysis. Uppsala Journal of Medical Sciences, 119, 251-261. https://doi.org/10.3109/03009734.2014.922649

[19] Chen, Y., Liang, M., Zhu, Y. and Zhou, D. (2015) The Effect of Propofol and Sevoflurane on the Perioperative Immunity in Patients under Laparoscopic Radical Resection of Colorectal Cancer. Chinese Medical Journal, 95, 3440-3444.

[20] Yan, T., Zhang, G.H., Wang, B.N., Sun, L. and Zheng, H. (2018) Effects of Propofol/Remifentanil-Based Total Intravenous Anesthesia versus Sevoflurane-Based Inhalational Anesthesia on the Release of VEGF-C and TGF-Beta and Prognosis after Breast Cancer Surgery: A Prospective, Randomized and Controlled Study. BMC Anesthesiology, 18, 131. https://doi.org/10.1186/s12871-018-0588-3

[21] Zhao, Y. and Zhang, H. (2018) Propofol and Sevoflurane Combined with Remifentanil on the Pain Index, Inflammatory Factors and Postoperative Cognitive Function of Spine Fracture Patients. Experimental and Therapeutic Medicine, 15, 3775-3780. https://doi.org/10.3892/etm.2018.5898

[22] Bandschapp, O., Filitz, J., Ihmsen, H., Berset, A., Urwyler, A., Koppert, W. and Ruppen, W. (2010) Analgesic and Antihyperalgesic Properties of Propofol in a Human Pain Model. Anesthesiology, 113, 421-428. https://doi.org/10.1097/ALN.0b013e3181e33ac8

[23] Abreu, M., Aguado, D., Benito, J., García-Fernández, J. and De Segura, I.A.G. (2015) Hyperalgesia and Increased Sevoflurane Minimum Alveolar Concentration Induced by Opioids in the Rat: A Randomised Experimental Study. European Journal of Anaesthesiology (EJA), 32, 232-241. https://doi.org/10.1097/EJA.0000000000000188 